\title{
Preseismic TEC Changes for Tohoku-Oki Earthquake: Comparisons Between Simulations and Observations
}

\author{
Cheng-Ling Kuo ${ }^{1}$, Lou-Chuang Lee ${ }^{1,2, *}$, and Kosuke Heki ${ }^{3}$ \\ ${ }^{1}$ Institute of Space Science, National Central University, Jhongli, Taiwan \\ ${ }^{2}$ Institute of Earth Sciences, Academia Sinica, Taipei, Taiwan \\ ${ }^{3}$ Department of Natural History Science, Hokkaido University, Sapporo, Japan
}

Received 17 May 2013, revised 11 March 2014, accepted 19 August 2014

\begin{abstract}
Heki (2011) reported that the Japanese Global Positioning System (GPS) dense network detected a precursory positive total electron content anomaly (TEC), with $\triangle$ TEC 3 TECU, 40 minutes before the Tohoku-Oki earthquake (Mw 9.0). Similar preseismic TEC anomalies were also observed in the 2010 Chile earthquake (Mw 8.8), 2004 Sumatra-Andaman (Mw 9.2) and the 1994 Hokkaido-Toho-Oki (Mw 8.3). In this paper we apply our improved lithosphere-atmosphere-ionosphere (LAI) coupling model to compute the TEC variations and compare the simulation results with the reported TEC observations. For the Tohoku-Oki earthquake simulations we assumed that the stressed associated current started $\sim 40$ minutes before the earthquake, linearly increased and reached its maximum magnitude at the time of the earthquake main shock. It is suggested that a dynamo current density of $\sim 25 \mathrm{nA} \mathrm{m}^{-2}$ is required to produce the observed $\triangle \mathrm{TEC} \sim 3 \mathrm{TECU}$.
\end{abstract}

Key words: Earthquake precursor, Total electron content anomaly, Tohoku-Oki earthquake

Citation: Kuo, C. L., L. C. Lee, and K. Heki, 2015: Preseismic TEC changes for Tohoku-Oki earthquake: Comparisons between simulations and observations. Terr. Atmos. Ocean. Sci., 26, 63-72, doi: 10.3319/TAO.2014.08.19.06(GRT)

\section{INTRODUCTION}

The search for earthquake precursors has been conducted over several decades. Scientists have sought seismo-related signatures in the atmosphere or ionosphere and attempted to clarify possible earthquake precursor signatures. Insufficiency in observational evidence drives more interdisciplinary investigations attempting to unveil possible clues related to earthquake activities. Several measurement methods, including VLF/LF electromagnetic wave anomalies (Hayakawa et al. 2010, 2012), thermal anomalies (Ouzounov and Freund 2004; Ouzounov et al. 2006; Pulinets and Ouzounov 2011), TEC (total electron content) variations (Liu et al. 2000, 2001, 2004; Zhao et al. 2008) were investigated. In particular, the ionospheric TEC anomaly is one of the possible seismo-ionosphere coupling process manifestations (Pulinets and Boyarchuk 2004; Pulinets and Ouzounov 2011). Zhao et al. (2008) and Liu et al. (2009) reported that the TEC may have anomalously decreased or increased up to 5 - 20\% several days before the 2008 Wenchuan earthquake

\footnotetext{
* Corresponding author

E-mail:louclee@earth.sinica.edu.tw
}

(Mw 7.9). Recently, (Heki 2011) found that 40 minutes before the 2011 Tohoku-Oki earthquake (Mw 9.0) the Japanese Global Positioning System (GPS) dense network Geonet detected a clear precursory positive anomaly in the TEC. Similar preseismic TEC anomalies were also observed in the 2010 Chile (Mw 8.8), 2004 Sumatra-Andaman (Mw 9.2), and the 1994 Hokkaido-Toho-Oki (Mw 8.3) earthquakes. The TEC variation finding over the earthquake epicenter lacks physical mechanisms to explain these pre-earthquake ionospheric signatures.

Kuo et al. $(2011,2014)$ proposed an electric coupling model for the lithosphere-atmosphere-ionosphere (LAI) current system, as illustrated in Fig. 1. The lithosphere dynamo in the earthquake preparation region drives the internal current $\left(\mathrm{J}_{\mathrm{d}}\right)$ downward, leading to the presence of a charge dipole. Freund (2010) demonstrated that stressed rock can generate currents and serves as a current dynamo in the lithosphere. Due to the finite conductivities in the lithosphere, atmosphere and ionosphere, the current flows downward from the ionosphere, through the atmosphere $\left(\mathrm{J}_{1}\right)$ and the lithosphere, into the negative pole of the dynamo region. The current flowing out of the ionosphere will reduce the 
positive charges in the ionosphere which have a higher electric potential. The currents flowing in the atmosphere are obtained by directly solving the current continuity equation $\nabla \cdot \vec{J}=0$ (Kuo et al. 2014). The current obtained in the atmosphere can be used to calculate the electric fields at the lower boundary of the ionosphere. These external electric fields are them imposed as the boundary condition for the SAMI3 ionosphere model. The $\mathrm{E} \times \mathrm{B}$ plasma motion leads to TEC variations in the ionosphere.

In the present study, we use this LAI coupling model to obtain the ionospheric TEC variations 40 minutes before the 2011 Tohoku-Oki earthquake. Our modeling results are then compared with the observed ionospheric precursor signatures (TEC variations).

\section{THE JAPANESE GEONET TEC OBSERVATION FOR THE 2011 TOHOKU-OKI EARTHQUAKE}

With the aid of the Japanese dense GPS Geonet observation network (http://www.gsi.go.jp) a possible earthquake precursor anomaly could be detected for the 11 March 2011, Tohoku-Oki earthquake (Mw 9.0) (Heki 2011; Heki and Enomoto 2013). Heki (2011) used GPS-TEC data to find a clear precursory positive ionospheric TEC anomaly over the epicentral region. The TEC variations started $\sim 40$ minutes before the earthquake and reached nearly ten percent of the background TEC. At the time of the main shock (UT 05:46), eight GPS satellites were visible there (Heki 2011). The coseismic ionospheric disturbances (CIDs) can be seen by the GPS satellites as irregular TEC changes caused by acoustic waves $\sim 10$ minutes after the earthquake, and ionospheric oscillations caused by atmospheric waves or internal gravity waves 40 - 80 minutes after the earthquake.

Figure 2 shows the GPS trajectories of the sub-ionospheric points (SIP) assuming a thin layer at $300 \mathrm{~km}$ altitude. The near-by-passage of satellite 15 (red), 26 (green), and 27 (blue) are drawn as dots while the corresponding SIP are indicated by solid lines. Here we show the detailed GPS-TEC data associated with these GPS satellites; other GPS satellites have similar results. For Satellite 15, the time sequence for TEC variation geographical snapshots are shown in Fig. 3 from UT 05:06 - 06:00 with a time step of $\sim 5$ minutes. The Japanese Geonet has more than 1000 sites and the corresponding measured $\triangle \mathrm{TEC}$ are shown in Figs. 3 - 5 where each dot indicates the measured $\triangle \mathrm{TEC}$ with color scale in

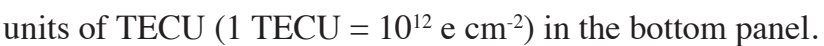

In Fig. 3, near the northeast side of Japan close to the west side of the 2011 Tohoku-Oki earthquake epicenter, the positive TEC anomaly is found to start 40 minutes before the earthquake (UT 05:46). The region with the increase in TEC grew in area and reached the maximum value of $\triangle T E C$. The TEC variations dissipated and returned to normal after the CID caused by atmospheric waves generated by the earthquake main shock (Calais and Minster 1995).
To confirm the TEC increases preceding the Earthquake, we also show the TEC measurement by Satellite 26 and 27 in Figs. 4 and 5. Similar results for the increased TEC were found in the covered region observed by Satellite 26 almost directly over the epicentral region. In the period from UT 05:46 - 05:51 the observed $\triangle$ TEC reached its peak value $\sim 5$ TECU. At the time of UT 06:00 it was found that CID generated by the earthquake main shock propagated outward, as shown in the dashed circle in Fig. 4. The oscillatory variations in the ionosphere caused by atmospheric waves started at the time $\sim 10$ minutes after the earthquake and lasted 40 - 80 minutes afterward (Heki 2011; Liu et al. 2011).

\section{SIMULATION RESULTS FROM LAI COUPLING MODEL}

When subjected to stress rocks can activate positive holes $\left(\mathrm{h}^{\circ}\right)$ as charge carriers and generate electric currents

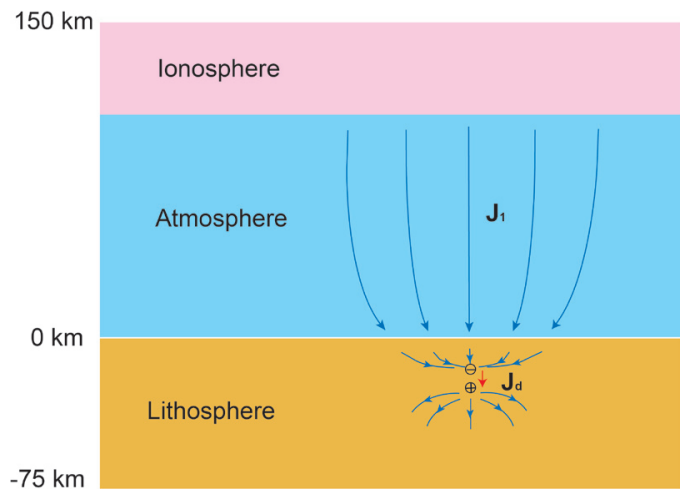

Fig. 1. The current flow in the lithosphere, atmosphere and ionosphere electric coupling model. The lithosphere dynamo has a charge dipole generated by the internal current $\mathrm{J}_{\mathrm{d}}$. The current flows downward from the ionosphere, through the atmosphere $\left(\mathrm{J}_{1}\right)$ and lithosphere into the negative pole of the dynamo region.

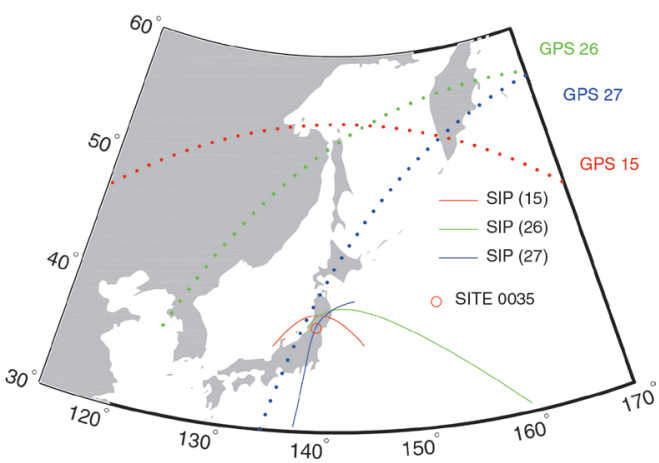

Fig. 2. The trajectories of sub-ionospheric points (SIP) assuming a thin layer at $300 \mathrm{~km}$ altitude for GPS satellites and given ground GPS site 0035. The near-by-passage of satellites 15, 26, and 27 are drawn as dots while the corresponding SIPs for GPS 15, 26, and 27 are indicated by solid lines. Within the dots and solid lines, the GPS satellites 15,26, and 27 are colorized as red, green and blue lines. 

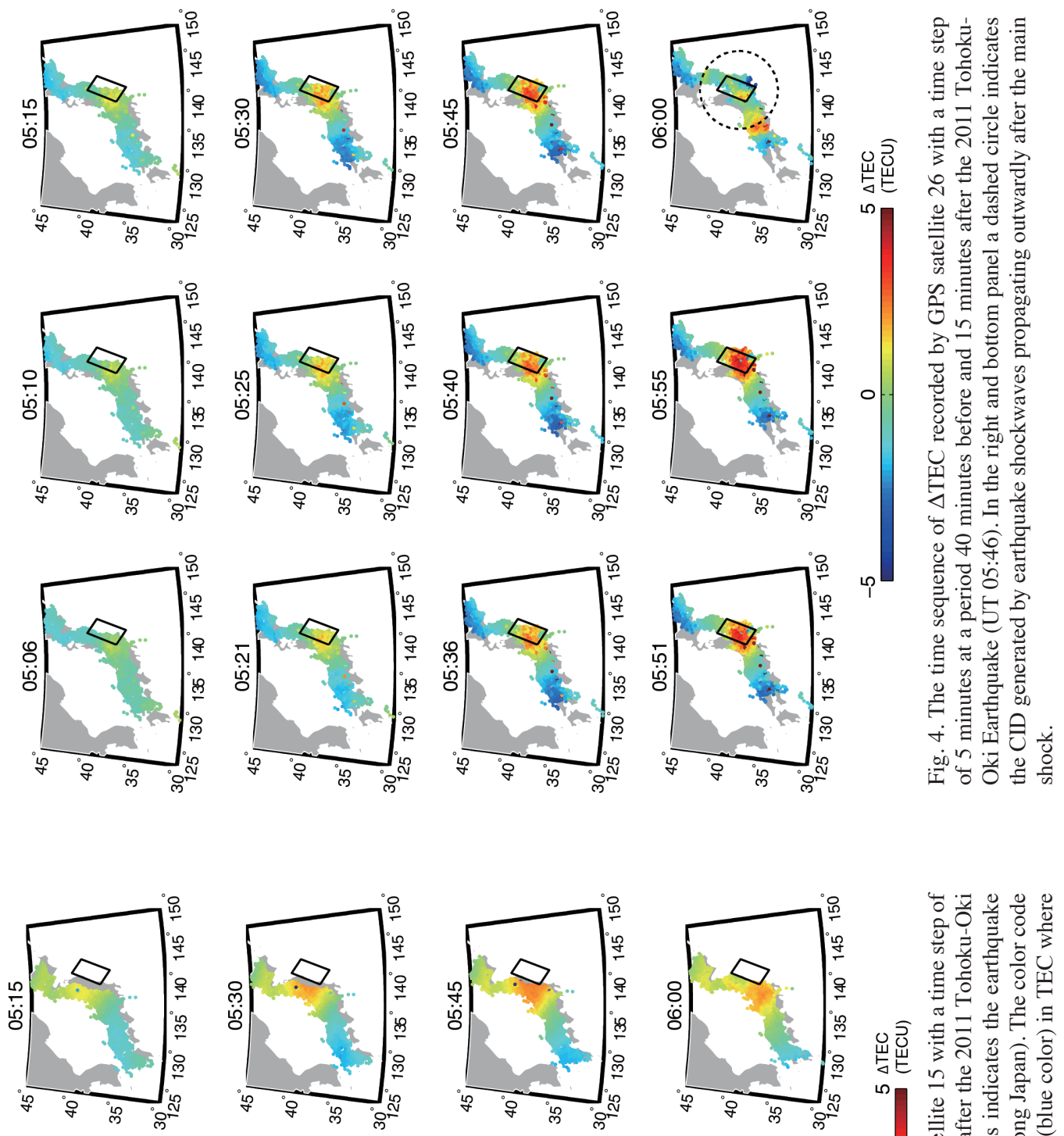

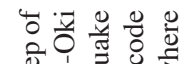

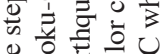

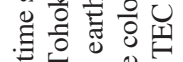

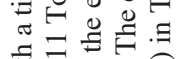

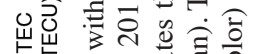

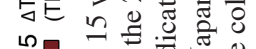

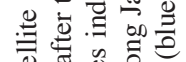
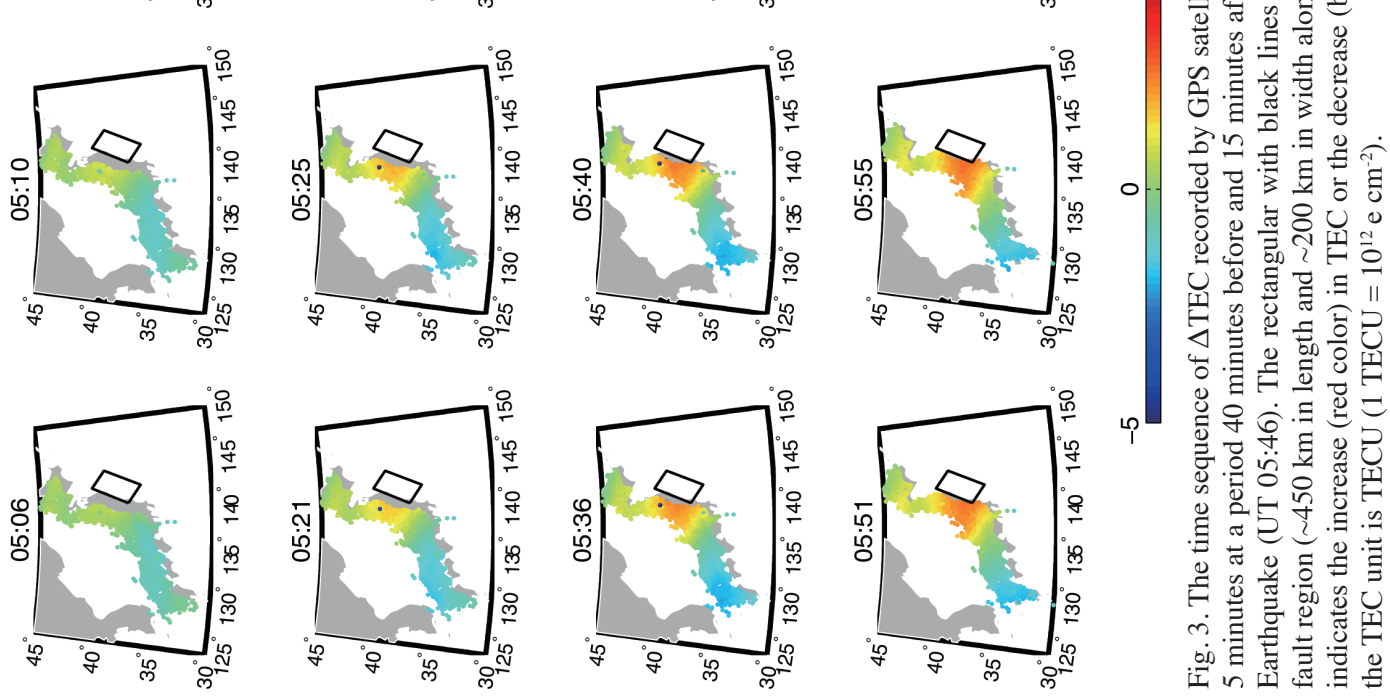

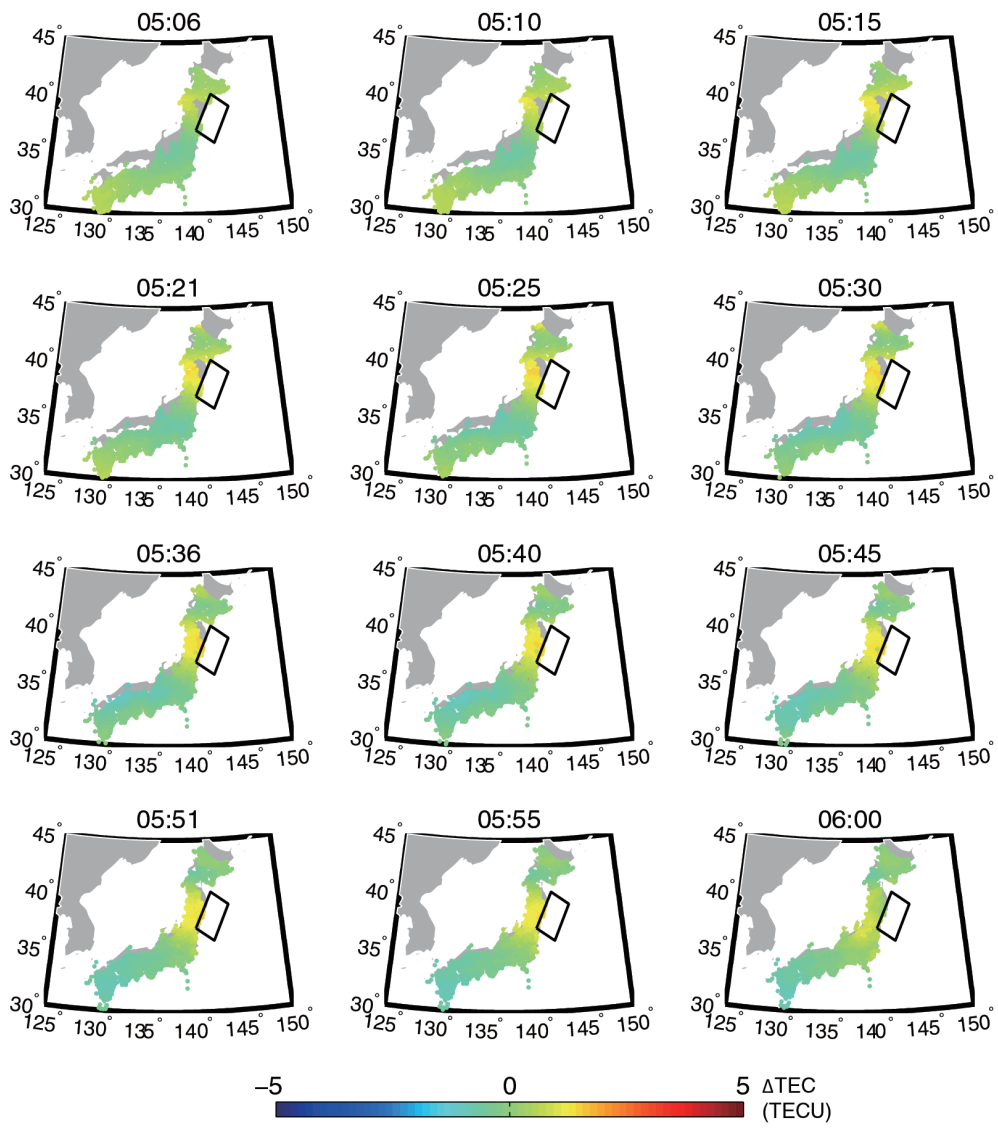

Fig. 5. The $\triangle$ TEC time sequence recorded by GPS satellite 27 with a time step of 5 minutes at a period 40 minutes before and 15 minutes after the 2011 Tohoku-Oki Earthquake (UT 05:46).

(Freund 2010). Positive hole charge carriers accumulated at the Earth's surface and charged $\mathrm{O}_{2}{ }^{+}$ions from field-ionization accumulated in the air near the region of stressed rock. As rocks are subjected to stress, rocks activate hole (h') charge carriers. With the exception of pure white marble, every igneous and high-grade metamorphic rock tested has produced hole $\left(h^{\circ}\right)$ charge carriers when stressed. The positive $\left(h^{\circ}\right)$ charge carriers can spread through any less stressed and even nominally unstressed rock. The unstressed rock becomes positively charged while the stressed rocks are negatively charged due to the loss of $\left(\mathrm{h}^{\circ}\right)$ charge carriers in the stressed region. Even in oceanic regions, e.g., the 2011 Tohoku-Oki earthquake in our case, charge carriers have higher mobility in the ocean than on land because of the higher conductivity of water. The accumulated surface charge over land or ocean would drive the current outward. After the charge neutralization time, some surface charges are transported into the ionosphere. The equivalent effect is the current flowing into the ionosphere. The direction of dynamo current flowing in the atmosphere depends on the sign of the generated charges over the Earth's surface near the stressed rock region: downward to (upward from) negative (positive) surface charge regions.

Kuo et al. (2014) improved the LIA system coupling model over the previous model (Kuo et al. 2011) which is valid only for magnetic latitude $90^{\circ}$ and underestimates the imposed electric field at the lower ionosphere boundary. In the new model currents in the atmosphere are calculated by directly solving the current continuity equation, $\nabla \cdot J=0$. The currents in the atmosphere can be solved for any arbitrary angle of magnetic field, i.e., any magnetic altitude. The dynamo current density required to generate the same amount of TEC variation is found to be smaller by a factor of $\sim 30$ compared to that obtained in our previous model. The typical dynamo current $J_{\max }$ value used in the calculations is $10-100 \mathrm{nA} \mathrm{m}^{-2}$, corresponding to $\triangle \mathrm{TEC}$ of $1-7$ TECU for the daytime ionosphere.

We used the electric coupling model (Kuo et al. 2011, 2014) to study the TEC increases before the 2011 TohokuOki Earthquake (Heki 2011). The simulation results in our coupling models were compared with the observed TEC from Geonet. The parameters in the atmosphere-ionosphere coupling model are listed below. The details in the atmospheric current model and the ionosphere model are described in section 3, respectively.

\subsection{The Atmospheric Current Model}

Our assumed atmospheric current model: 
(1) Fault region: $450 \mathrm{~km}$ in length and $200 \mathrm{~km}$ in width (Heki 2011), azimuth angle 30 degree from North.

(2) Shift $1.5^{\circ}$ west in longitude for EQ epicenter $\left(38.3^{\circ} \mathrm{N}\right.$, $\left.142.4^{\circ} \mathrm{E}\right)$ toward the land.

(3) Maximum current density $J_{\max }=25 \mathrm{nA} \mathrm{m}^{-2}$.

(4) Current density linearly increasing from zero to its maximum value in the 40-minute period (UT 05:06 - 05:46) before the main shock.

In our atmospheric current model we assume current distribution near the ground surface, which is confined to a region with the length $2 a$ and the width $2 b$.

$J_{\text {surf }}(x, y)=\frac{-J_{\max }}{4}\left[1+\cos \frac{\pi\left(x-x_{0}\right)}{a}\right]\left[1+\cos \frac{\pi\left(y-y_{0}\right)}{b}\right]$

for $x_{0}-a<x<x_{0}+a$ and $y_{0}-b<y<y_{0}+b$, where the center $\left(x_{0}, y_{0}\right)$ of charge region is located near the epicenter. The negative sign in the above equation indicates the current flowing downward. The maximum current density $J_{\max }$ is $25 \mathrm{nA} \mathrm{m}^{-2}$, and the total current can be integrated as $I=a \times b \times J_{\max }$. We assume a generated current source region with $a=200 \mathrm{~km}$ and $b=450 \mathrm{~km}$, which is about the size of the fault region for the Tohoku-Oki earthquake.
The current system in the atmosphere is numerically solved using $\nabla \cdot J=0$ in 3D Cartesian coordinates $(x, y, z)$ where the $x$-axis is east - west, the $y$-axis is north - south, $-1000 \leq x, y \leq 1000 \mathrm{~km}$, and the $z$-axis is the altitude, $0 \leq z \leq 200 \mathrm{~km}$. The upper ionospheric boundary condition is $\frac{\partial J_{z}}{\partial z}=0$. Figure 6 shows an example of dynamo current with $J_{\max }=25 \mathrm{nA} \mathrm{m}{ }^{-2}, a=200 \mathrm{~km}$ and $b=450 \mathrm{~km}$ : Fig. $6 \mathrm{a}$ for the current density in the $y=0$ plane, and Fig. $6 \mathrm{~b}$ for that in the $x=0$ plane, and the white lines indicate the current flows. The peak current density at altitude $z=85 \mathrm{~km}$ is about $-12.5 \mathrm{nA} \mathrm{m}^{-2}$.

The nearly upward or downward current $J$ flowing at $85 \mathrm{~km}$ altitude generally makes an angle with the inclined magnetic field. The imposed electric field on the lower boundary of the ionosphere can be derived by $E=\stackrel{\leftrightarrow}{\sigma}^{-1} J$ where conductivity tensor $\overleftrightarrow{\sigma}$ is expressed by (Park and Dejnakarintra 1973),

$\overleftrightarrow{\sigma}=\left[\begin{array}{ccc}\sigma_{1} & \sigma_{2} \sin \theta_{b} & \sigma_{2} \cos \theta_{b} \\ -\sigma_{2} \sin \theta_{b} & \sigma_{1} \sin ^{2} \theta_{b}+\sigma_{0} \cos ^{2} \theta_{b} & \left(\sigma_{1}-\sigma_{0}\right) \sin \theta_{b} \cos \theta_{b} \\ -\sigma_{2} \cos \theta_{b} & \left(\sigma_{1}-\sigma_{0}\right) \sin \theta_{b} \cos \theta_{b} & \sigma_{1} \cos ^{2} \theta_{b}+\sigma_{0} \sin ^{2} \theta_{b}\end{array}\right]$

where $\sigma_{0}, \sigma_{1}$, and $\sigma_{2}$ are the conductivity along the

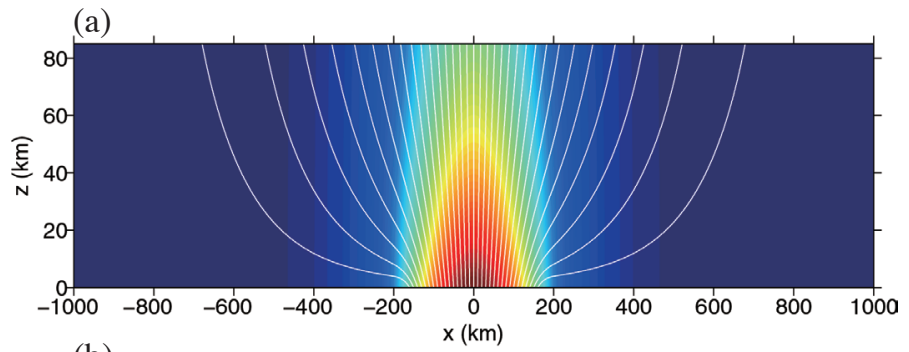

(b)

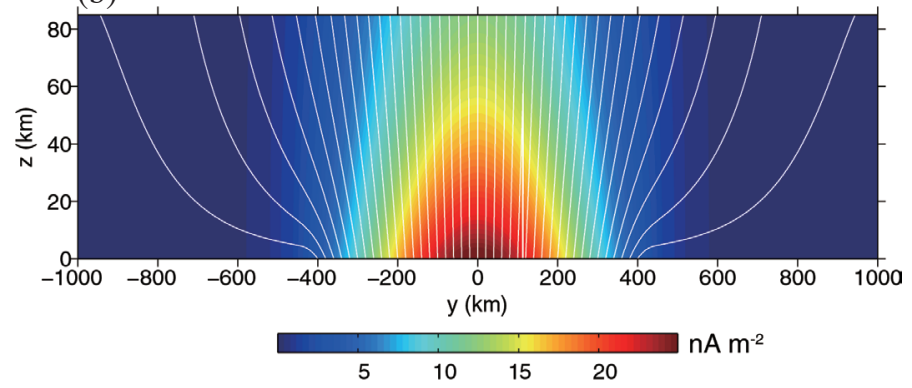

(c)

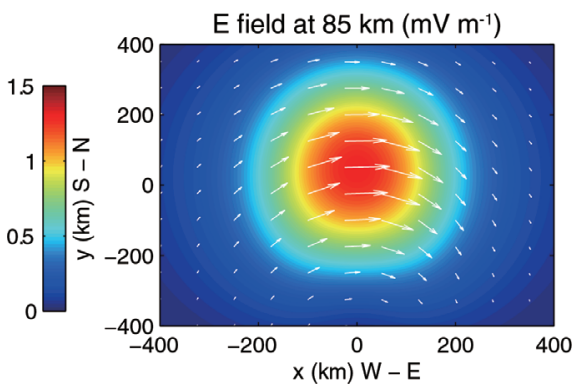

Fig. 6. The distribution of current densities in (a) the $y=0$ plane and (b) the $x=0$ plane of the atmosphere. The current density is expressed in colors and the white lines are current flow lines. (c) The eastward electric field at an altitude of $85 \mathrm{~km}$. 
magnetic field, Pedersen conductivity and Hall conductivity, respectively; $\theta_{b}$ is the inclined angle of the magnetic field line and the horizontal plane. The values of the elements of $\vec{\sigma}$ are adopted from the SAMI3 ionosphere model (see below). Figure $6 \mathrm{c}$ shows the imposed electric field on the upper (lower) boundary of the atmosphere (ionosphere) for the current distribution in Figs. 6a and b.

The imposed electric field at the lower ionosphere boundary can be used to study the TEC variations. The conductivity along the magnetic field-of-line in the ionosphere is very high. The potential along the field-of-line has nearly equal potential. The imposed electric field can change the electric field potential along the field-of-line in the ionosphere. Therefore, we impose the electric field caused by the upward current from the lower atmosphere, which served as the electric disturbance source in the ionosphere.

\subsection{The Ionosphere Model Coupling with Atmospheric Current System}

The parameters in the ionosphere model (SAMI3) are: (1) Day 70 (11 March) in 2011.

(2) Solar photoionization in the ionosphere (TEC): F10.7 index $=150$, and $\mathrm{F} 10.7 \mathrm{~A}=150$ (81-day average of the daily F10.7).

(3) Geomagnetic Disturbance Index: AP $=4$ (mild geomagnetic condition).

(4) Neutral wind model: HWM07.

(5) Simulation region $+/-8^{\circ}$ in longitude, grid size $(n f, n z, n l)=(240,101,70)$.

The NRL three-dimensional ionosphere simulation code SAMI3 (http://wwwppd.nrl.navy.mil/sami2-OSP/index.html), including ion dynamics and electric potential, is used to investigate the TEC variation caused by the electric field from the earthquake fault zone source charge. We solve the current continuity equation $(\nabla \cdot J=0)$ in the ionosphere (Huba et al. 2008, 2009a, b, c) and obtain the electric potential in the SAMI3 ionosphere model. The resulting electric field is used to study the plasma motion in the ionosphere caused by the earthquake fault zone source charge.

\section{COMPARISONS BETWEEN MODELING RESULTS AND THE OBSERVATION}

The 2011 Tohoku-Oki earthquake had a fault region of $\sim 450 \mathrm{~km}$ in length and $\sim 200 \mathrm{~km}$ in width along the Japan Trench where the Pacific Plate subducts beneath NE Japan, as modeled above (Heki 2011). The fault region orientation has an azimuth angle $\sim 30$ degree from north centered at epicenter $\left(38.3^{\circ} \mathrm{N}, 142.4^{\circ} \mathrm{E}\right)$. It is assumed that the maximum current density $J_{\max }=25 \mathrm{nA} \mathrm{m}^{-2}$ increases linearly from zero to its maximum value in the 40-minute period (UT 05:06 - 05:46) before the main shock, as shown in Fig. 7, since the increase in TEC is found to start at the time 40 minutes before the earthquake (UT 05:46), and the region with the TEC increase grew in area and reached the maximum of $\triangle \mathrm{TEC}$.

\subsection{Simulation Results for Currents from the Atmosphere}

In comparison with the simulation results of Kuo et al. (2014), the modeling results show the presence of an eastward (westward) electric field for downward (upward) dynamo current flowing from the atmosphere into the ionosphere. At magnetic latitude $30^{\circ}$, close to the epicenter, the imposed eastward (westward) electric field causes the nearly upward-northward or downward-southward direction of $\mathrm{E} \times \mathrm{B}$ motion for ionospheric plasma, shown in Fig. 8a. For the nearly upward-northward plasma motion direction with eastward electric field caused by the downward current, the $\mathrm{E} \times \mathrm{B}$ motion drives the ionospheric plasma from the higher density region to the lower density region, enhancing the plasma density (Fig. 8c) and increasing the TEC (Fig. $8 b)$. Hence, we choose the downward current with eastward electric field as our dynamo current.

The typical dynamo current $J_{\max }$ value used in the calculations is $10-100 \mathrm{nA} \mathrm{m}^{-2}$, corresponding to $\triangle \mathrm{TEC}$ up to

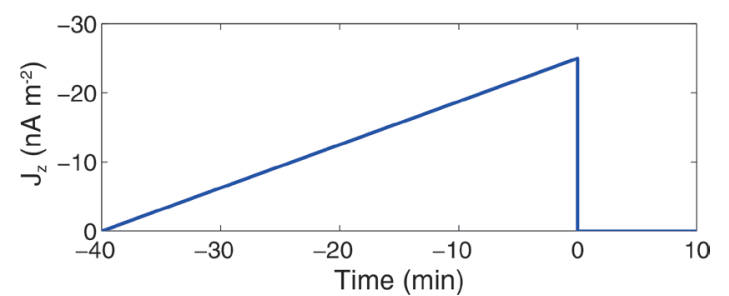

Fig. 7. The maximum current density linearly increases from zero to its maximum value in the 40-minute period (UT 05:06 - 05:46) before the main shock.

(a)

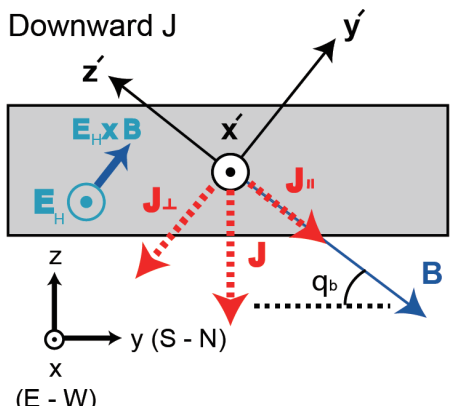

Fig. 8. The ionospheric anomaly caused by downward current at the magnetic latitude $30^{\circ}$; (a) the downward current lead to the presence of eastward electric field and the caused $\mathrm{E} \times \mathrm{B}$ motion enhance the ionospheric plasma density; (b) contour plots of $\triangle \mathrm{TEC}$ in TECU units where the open circle indicates the source region; (c) contour plots of electron density $n_{e}$ in the meridional planes; (d) contour plots of electron density variations $\Delta n_{e}$ in the meridional planes; (e) temperature variations in the meridional planes. 

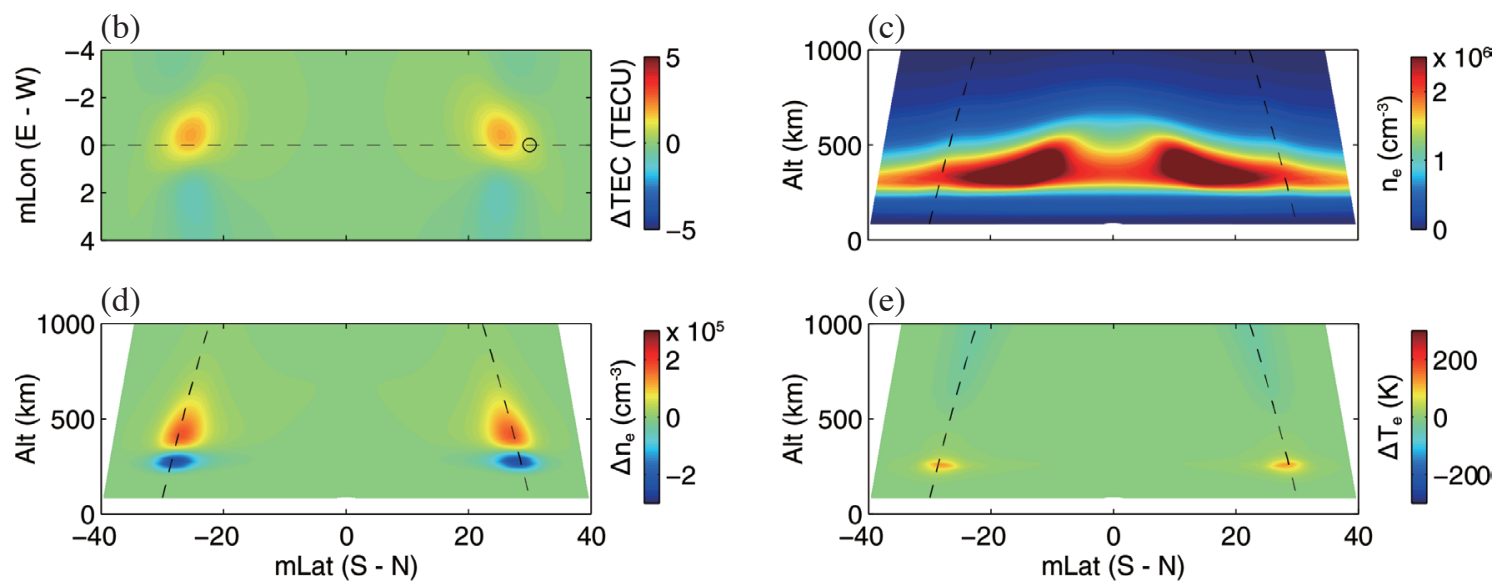

Fig. 8. (Continued)

1 - 7 TECU in the daytime case, shown in Fig. 9. In the nighttime case the smaller dynamo current $\left(1-10 \mathrm{nA} \mathrm{m}^{-2}\right)$ value can lead to similar $\triangle T E C$ values. In our calculation the dynamo current equals the ionospheric conductivity multiplication and caused an electric field. The typical daytime ionospheric conductivity is ten times that of the nighttime conductivity. Therefore, greater current density is required to reach the equivalent $\triangle T E C$ for the daytime ionosphere.

\subsection{Observation Results in Comparison with Simulation Results}

Figures 10a - $\mathrm{c}$ show the observed TEC variations at SIP of more than 1000 ground GPS sites in the Japanese Geonet and their corresponding $\triangle T E C$ measurements are indicated by the colored dots in TECU units. Figures $10 \mathrm{~d}-\mathrm{f}$ show the TEC contour lines from the simulation. Figures $10 \mathrm{e}-\mathrm{i}$ show the filled color TEC contours where the color code indicates the TECU value. The applied eastward electric field leads to the upward $\mathrm{E} \times \mathrm{B}$ motion and the increase in TEC. The $\triangle$ TEC shown in Figs. $10 \mathrm{~g}$ - $\mathrm{i}$ can be used to compare with the measured $\triangle$ TEC results in Figs. 10a - c.

Figure 11 shows a comparison of $\triangle \mathrm{TEC}$ profiles from modeling results (red dots) with the observations (blue dots) in TECU units one minute before the main shock. Figure $11 \mathrm{a}$ is for the profile at geolontitude $139^{\circ}$, Fig. $11 \mathrm{~b}$ at $140^{\circ}$, and Fig. $11 \mathrm{c}$ at $141^{\circ}$. Figures $11 \mathrm{~d}-\mathrm{f}$ are for the profiles at geolatitude 36,38 , and $40^{\circ}$. The modeling results with $J_{\max } \approx 25 \mathrm{nA} \mathrm{m}^{-2}$ are approximately matched with observations results.

\section{SUMMARY AND DISCUSSIONS}

Heki (2011) reported that $\sim 40$ minutes before the 2011 Tohoku-Oki earthquake the Japanese GPS dense network detected clear earthquake precursor signals for positive TEC variations over the epicentral region. We used the LAI coupling model to reproduce the observed $\triangle T E C 40$ minutes before the 2011 earthquake. We assumed the dynamo current area is similar to the earthquake fault region with a length $2 a$ and a width $2 b$ where $a=200 \mathrm{~km}$ and $b=450 \mathrm{~km}$. The required dynamo current was found to have a magnitude of $10-100 \mathrm{nA} \mathrm{m}{ }^{-2}$ producing $\triangle$ TEC of $1-7$ TECU. In order to explain the observed $\triangle$ TEC $\sim 3$ TECU by Heki (2011) and Heki and Enomoto (2013), the dynamo current with $J_{\max }=25 \mathrm{nA} \mathrm{m}^{-2}$ is required.

There are several areas for improvement and future study. First in our study we have to assume a dynamo current source. More work on the dynamo source in the Earth's lithosphere is needed. The assumed underground dynamo current source is based only on stressed rock experimental evidence obtained by Freund (2010) and the references therein.

Second it is assumed in the SAMI3 ionosphere model that conductivity along the magnetic field is infinite and the associated electric field along the magnetic field is zero. In the real ionosphere we should consider the finite conductivity along the magnetic field. The currents from the earthquake region flow into the ionosphere. Part of the currents flow along the magnetic field, reflected from the ionosphere of the opposite hemisphere and return to the current injection region. Although our simulation results show the conjugate

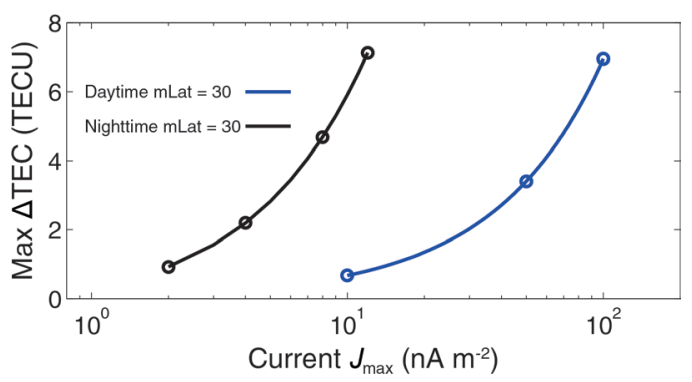

Fig. 9. The maximum $\triangle$ TEC (TECU) varies with source current density $J_{\max }$ in units of $\mathrm{nA} \mathrm{m}^{-2}$ where the solid lines are for $\triangle \mathrm{TEC}$ at magnetic latitude $30^{\circ}$. The blue (black) lines are for daytime (nighttime) ionosphere. 

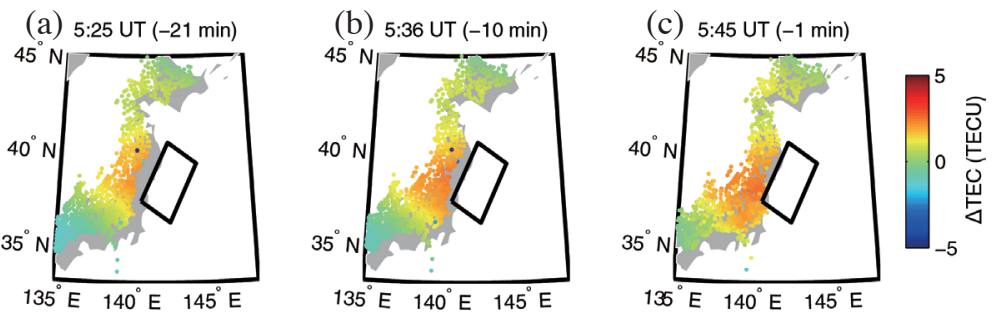

(d)

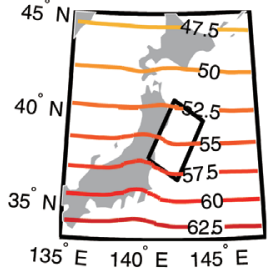

(e)

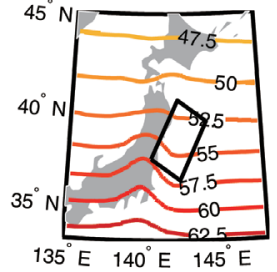

(f)

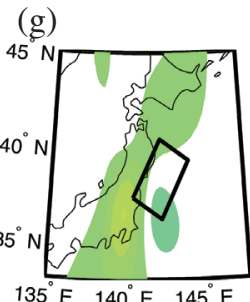

(h)
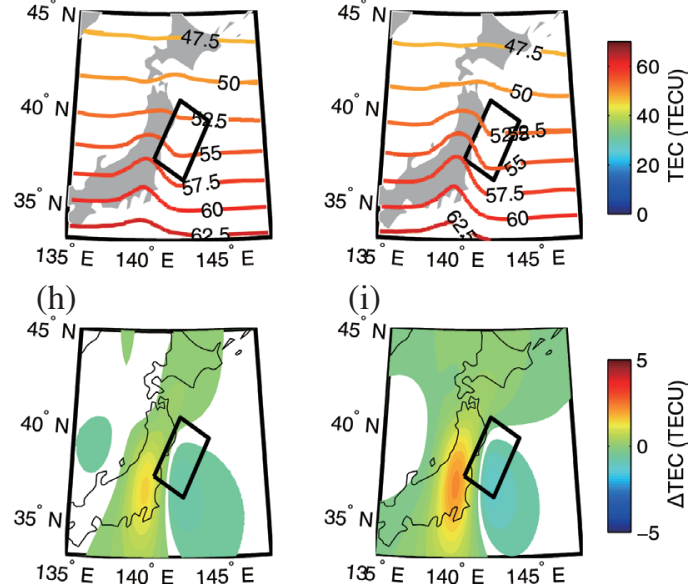

(i)

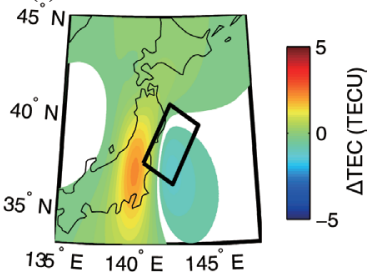

Fig. 10. The observed $\triangle$ TEC results from the Japanese Geonet where color code indicates the TEC magnitude in a time sequence of (a) 21 minutes, (b) 10 minutes, and (c) 1 minute before the main shock of the earthquake. The corresponding TEC contour lines from our simulation results are plotted in (d), (e), and (f). The corresponding $\triangle$ TEC from our simulation results are plotted in (g), (h), and (i).

(a)
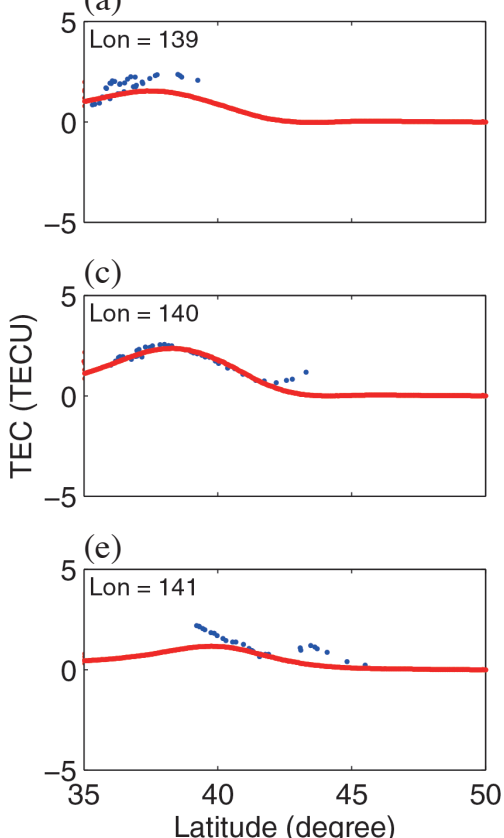

(b)

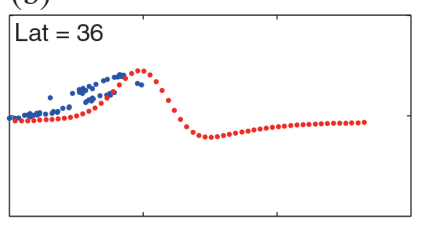

(d)

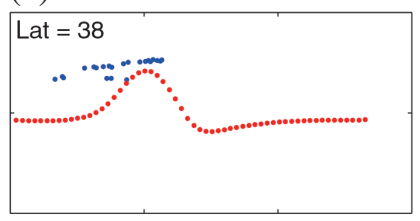

(f)

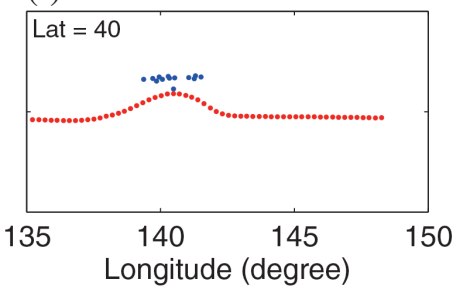

Fig. 11. Modeling results comparison (red dots) with observed $\triangle$ TEC (blue dots) in TECU units at UT 05:45, one minute before the time of main shock: (a) the profile at geolontitude $139^{\circ}$, (b) the profile at geolontitude $140^{\circ}$, (c) the profile at geolontitude $141^{\circ}$, (d) the profile at geolatitude $36^{\circ}$, (e) the profile at geolatitude $38^{\circ}$, and (f) the profile at geolatitude $40^{\circ}$. 
effect, such as plasma and temperature variations, in the opposite hemisphere, as shown in Fig. 8, the conjugate effect may be decreased due to a finite field-aligned conductivity.

Third it is suggested that simultaneous measurements be carried out on the underground dynamo current and electric field, the current and electric field above the Earth's surface and ionosphere TEC from ground GPS sites. These coordinated observations will help to resolve the linkage among the dynamo current in the lithosphere, currents in the atmosphere and TEC variations in the ionosphere.

Acknowledgements We acknowledge discussions with Ben Chao, Li Zhao, Tiger Liu, Cheng-Horng Lin, and Chieh-Hung Chen. We are grateful to the National Center for High-performance Computing in Taiwan and the Center for Computational Geophysics at National Central University for computing support. This work is supported in part by grants (NSC 101-2628-M-001-007-MY3, NSC 1022119-M-001-014, and NSC 102-2111-M-008-016) from the Ministry of Science and Technology of Taiwan.

\section{REFERENCES}

Calais, E. and J. B. Minster, 1995: GPS detection of ionospheric perturbations following the January 17, 1994, Northridge Earthquake. Geophys. Res. Lett., 22, 1045 1048, doi: 10.1029/95g100168. [Link]

Freund, F., 2010: Toward a unified solid state theory for pre-earthquake signals. Acta Geophys., 58, 719-766, doi: 10.2478/s11600-009-0066-x. [Link]

Hayakawa, M., Y. Kasahara, T. Nakamura, F. Muto, T. Horie, S. Maekawa, Y. Hobara, A. A. Rozhnoi, M. Solovieva, and O. A. Molchanov, 2010: A statistical study on the correlation between lower ionospheric perturbations as seen by subionospheric VLF/LF propagation and earthquakes. J. Geophys. Res., 115, A09305, doi: 10.1029/2009ja015143. [Link]

Hayakawa, M., Y. Kasahara, T. Endoh, Y. Hobara, and S. Asai, 2012: The observation of Doppler shifts of subionospheric LF signal in possible association with earthquakes. J. Geophys. Res., 117, A09304, doi: 10.1029/2012ja017752. [Link]

Heki, K., 2011: Ionospheric electron enhancement preceding the 2011 Tohoku-Oki earthquake. Geophys. Res. Lett., 38, L17312, doi: 10.1029/2011g1047908. [Link]

Heki, K. and Y. Enomoto, 2013: Preseismic ionospheric electron enhancements revisited. J. Geophys. Res., 118, 6618-6626, doi: 10.1002/jgra.50578. [Link]

Huba, J. D., G. Joyce, and J. Krall, 2008: Three-dimensional equatorial spread $F$ modeling. Geophys. Res. Lett., 35, L10102, doi: 10.1029/2008GL033509. [Link]

Huba, J.D., J. Krall, and G. Joyce, 2009a: Atomic and molecular ion dynamics during equatorial spread $F$. Geophys. Res. Lett., 36, 10106, doi: 10.1029/2009GL037675.
[Link]

Huba, J. D., G. Joyce, J. Krall, and J. Fedder, 2009b: Ion and electron temperature evolution during equatorial spread F. Geophys. Res. Lett., 36, L15102, doi: 10.1029/2009GL038872. [Link]

Huba, J. D., S. L. Ossakow, G. Joyce, J. Krall, and S. L. England, 2009c: Three-dimensional equatorial spread $F$ modeling: Zonal neutral wind effects. Geophys. Res. Lett., 36, L19106, doi: 10.1029/2009GL040284. [Link]

Kuo, C. L., J. D. Huba, G. Joyce, and L. C. Lee, 2011: Ionosphere plasma bubbles and density variations induced by pre-earthquake rock currents and associated surface charges. J. Geophys. Res., 116, A10317, doi: 10.1029/2011ja016628. [Link]

Kuo, C. L., L. C. Lee, and J. D. Huba, 2014: An improved coupling model for the lithosphere-atmosphere-ionosphere system. J. Geophys. Res., 119, 3189-3205, doi: 10.1002/2013JA019392. [Link]

Liu, J. Y., Y. I. Chen, S. A. Pulinets, Y. B. Tsai, and Y. J. Chuo, 2000: Seismo-ionospheric signatures prior to $\mathrm{M} \geq 6.0$ Taiwan earthquakes. Geophys. Res. Lett., 27, 3113-3116, doi: 10.1029/2000GL011395. [Link]

Liu, J. Y., Y. I. Chen, Y. J. Chuo, and H. F. Tsai, 2001: Variations of ionospheric total electron content during the Chi-Chi earthquake. Geophys. Res. Lett., 28, 13831386, doi: 10.1029/2000GL012511. [Link]

Liu, J. Y., Y. J. Chuo, S. J. Shan, Y. B. Tsai, Y. I. Chen, S. A. Pulinets, and S. B. Yu, 2004: Pre-earthquake ionospheric anomalies registered by continuous GPS TEC measurements. Ann. Geophys., 22, 1585-1593, doi: 10.5194/angeo-22-1585-2004. [Link]

Liu, J. Y., Y. I. Chen, C. H. Chen, C. Y. Liu, C. Y. Chen, M. Nishihashi, J. Z. Li, Y. Q. Xia, K. I. Oyama, K. Hattori, and C. H. Lin, 2009: Seismoionospheric GPS total electron content anomalies observed before the 12 May $2008 M_{w} 7.9$ Wenchuan earthquake. J. Geophys. Res., 114, A04320, doi: 10.1029/2008JA013698. [Link]

Liu, J. Y., C. H. Chen, C. H. Lin, H. F. Tsai, C. H. Chen, and M. Kamogawa, 2011: Ionospheric disturbances triggered by the 11 March 2011 M9.0 Tohoku Earthquake. J. Geophys. Res., 116, A06319, doi: 10.1029/2011JA016761. [Link]

Ouzounov, D. and F. Freund, 2004: Mid-infrared emission prior to strong earthquakes analyzed by remote sensing data. Adv. Space Res., 33, 268-273, doi: 10.1016/ S0273-1177(03)00486-1. [Link]

Ouzounov, D., N. Bryant, T. Logan, S. Pulinets, and P. Taylor, 2006: Satellite thermal IR phenomena associated with some of the major earthquakes in 19992003. Phys. Chem. Earth, 31, 154-163, doi: 10.1016/j. pce.2006.02.036. [Link]

Park, C. G. and M. Dejnakarintra, 1973: Penetration of thundercloud electric fields into the ionosphere and magnetosphere: 1. Middle and subauroral latitudes. 
J. Geophys. Res., 78, 6623-6633, doi: 10.1029/ JA078i028p06623. [Link]

Pulinets, S. and K. Boyarchuk, 2005: Ionospheric Precursors of Earthquakes, Springer, Berlin, 315 pp.

Pulinets, S. and D. Ouzounov, 2011: Lithosphere-Atmosphere-Ionosphere Coupling (LAIC) model - An unified concept for earthquake precursors validation.
J. Asian Earth Sci., 41, 371-382, doi: 10.1016/j.jseaes.2010.03.005. [Link]

Zhao, B., M. Wang, T. Yu, W. Wan, J. Lei, L. Liu, and B. Ning, 2008: Is an unusual large enhancement of ionospheric electron density linked with the 2008 great Wenchuan earthquake? J.Geophys. Res., 113, A11304, doi: 10.1029/2008JA013613. [Link] 